\title{
Overexpression of Serum Response Factor Restores Ocular Dominance Plasticity in a Model of Fetal Alcohol Spectrum Disorders
}

\author{
Arco P. Paul, ${ }^{1 \star}$ Fernanda Pohl-Guimaraes, ${ }^{1 *}$ Thomas E. Krahe, ${ }^{1}$ Claudio C. Filgueiras, ${ }^{1,2}$ Crystal L. Lantz, ${ }^{1}$ \\ Raymond J. Colello, ${ }^{1}$ Weili Wang, ${ }^{1}$ and Alexandre E. Medina ${ }^{1}$ \\ ${ }^{1}$ Department of Anatomy and Neurobiology, Virginia Commonwealth University School of Medicine, Richmond, Virginia 23298-0709, and ${ }^{2}$ Department of \\ Physiology, Universidade do Estado do Rio de Janeiro, Rio de Janeiro, RJ 20550-170, Brazil
}

\begin{abstract}
Neuronal plasticity deficits underlie many of the neurobehavioral problems seen in fetal alcohol spectrum disorders (FASD). Recently, we showed that third trimester alcohol exposure leads to a persistent disruption in ocular dominance (OD) plasticity. For instance, a few days of monocular deprivation results in a robust reduction of cortical regions responsive to the deprived eye in normal animals, but not in ferrets exposed early to alcohol. This plasticity deficit can be reversed if alcohol-exposed animals are treated with a phosphodiesterase type 1 (PDE1) inhibitor during the period of monocular deprivation. PDE1 inhibition can increase cAMP and cGMP levels, activating transcription factors such as the cAMP response element binding protein (CREB) and the serum response factor (SRF). SRF is important for many plasticity processes such as LTP, LTD, spine motility, and axonal pathfinding. Here we attempt to rescue OD plasticity in alcohol-treated ferrets using a Sindbis viral vector to express a constitutively active form of SRF during the period of monocular deprivation. Using optical imaging of intrinsic signals and single-unit recordings, we observed that overexpression of a constitutively active form of SRF, but neither its dominant-negative nor GFP, restored OD plasticity in alcohol-treated animals. Surprisingly, this restoration was observed throughout the extent of the primary visual cortex and most cells infected by the virus were positive for GFAP rather than NeuN. This finding suggests that overexpression of SRF in astrocytes may reduce the deficits in neuronal plasticity seen in models of FASD.
\end{abstract}

\section{Introduction}

Fetal alcohol spectrum disorders (FASD) is considered the leading cause of mental retardation in the Western world with as many as 40,000 cases per year in the United States (Klug and Burde, 2003). The sensory cortex is one of the most affected areas in FASD and children with this condition present altered somatosensory, auditory and visual processing (Mattson et al., 1996; Uecker and Nadel, 1996; Coles et al., 2002; Rasmussen et al., 2006). There is growing evidence indicating that these sensory problems may be related to poor cortical map refinement, organization and plasticity (Rema and Ebner, 1999; Medina et al., 2003, 2005; Powrozec and Zhou, 2005; Margret et al., 2006). We have developed a ferret model of FASD that provides a novel approach to test mechanistically how early alcohol exposure can impair sensory cortex function. We showed that Ferrets exposed

\section{Received Nov. 24, 2009; accepted Dec. 21, 2009.}

This work was supported by National Institutes of Health (NIH) (National Institute on Alcohol Abuse and Alcoholism) Grant AA-13023 to A.E.M. Microscopy was performed at Virginia Commonwealth University Department of Anatomy and Neurobiology Microscopy Facility, supported, in part, with funding of the NIH (National Institute of Neurological Disorders and Stroke) (enter Core Grant 5P30NSD47463-02.

*A.P.P. and F.P.-G. contributed equally to the study.

Correspondence should be addressed to Alexandre E. Medina, Department of Anatomy and Neurobiology, Box 0709, Virginia Commonwealth University, 1101 East Marshall Street, Room 12-044, Richmond, VA 23298-0709. E-mail: amedina@vcu.edu.

DOI:10.1523/JNEUROSCI.5840-09.2010

Copyright $\odot 2010$ the authors $\quad 0270-6474 / 10 / 302513-08 \$ 15.00 / 0$ to alcohol during the third trimester equivalent of human gestation present disorganization of orientation selectivity columns and impaired ocular dominance (OD) plasticity (Medina et al., 2003, 2005; Medina and Ramoa, 2005; Medina and Krahe, 2008). Importantly, both of these cortical features can be rescued by vinpocetine, a phosphodiesterase type 1 inhibitor, even several weeks after alcohol exposure (Medina et al., 2006; Krahe et al., 2009). The efficacy of vinpocetine can be attributed by an increase in cAMP and cGMP levels, which in turn, would result in activation of the transcription factors $\mathrm{cAMP} / \mathrm{Ca}^{2+}$ response element-binding protein (CREB) and serum response factor (SRF) (Chai and Tarnawski, 2002; Kornhauser et al., 2002). Importantly, while cross talks between the cascades exist it is safe to say the CREB and SRF can be preferentially activated by cAMP and cGMP respectively. Recently, we discovered that, contrary to what was observed with vinpocetine, Rolipram, a PDE type 4 inhibitor failed to restore OD plasticity in the ferret model of FASD (Krahe et al., 2010). Since Rolipram increases only cAMP levels and not cGMP, one may suggest that the restoration of plasticity seen earlier is due to SRF activation. While the association of CREB with neuronal plasticity has been in the spotlight for decades (Frank and Greenberg, 1994; Silva et al., 1998; Shaywitz and Greenberg, 1999; Lamprecht, 2005), much less is known regarding SRF. This is surprising, given that many genes necessary for plasticity-related events require activation of both of these transcription factors (Montminy et al., 1990; Platenik et al., 
2000; Chai and Tarnawski, 2002). Recently many studies have shown the importance of SRF for LTP, LTD, spine motility and axonal pathfinding (Alberti et al., 2005; Ramanan et al., 2005; Etkin et al., 2006; Knöll et al., 2006). In fact SRF can mediate the expression of many plasticity-related factors such as neurotrophins, immediate early genes, cytoskeletal proteins and trombospondins (Morris et al., 1999; Chai and Tarnawski, 2002; Schratt et al., 2002; Christopherson et al., 2005; Ramanan et al., 2005; Knöll et al., 2006; Stritt et al., 2009). Here, we use viral-mediated gene transfer to overexpress a constitutively active form of SRF in visual cortex, to reverse the OD plasticity deficits seen in a ferret model of FASD.

\section{Materials and Methods}

All procedures described in this paper were approved by the Institutional Animal Care and Use Committee at Virginia Commonwealth University. For a summary of our experimental design, see Figure 1A. Briefly, ferrets were treated with $3.5 \mathrm{~g} / \mathrm{kg}$ alcohol intraperitoneally ( $25 \%$ in saline) or saline as control every other day between postnatal day (P) 10 to P30. This alcohol treatment lead to a blood alcohol level of $\sim 250 \mathrm{mg} / \mathrm{dl}$ for $1-5 \mathrm{~h}$ after injection (Medina et al., 2003). At the peak of critical period of the OD plasticity (P38-P45), animals were injected in V1 with a Sindbis virus carrying a constitutively active form of SRF, a dominant-negative (SRF-), or a control GFP.

Viruses were made and kindly provided by Drs. Amit Etkin and Eric Kandel (Columbia University, New York, NY). The construct was made by fusing the dimerization and DNA binding domains of SRF (aa 90222) with the HSV VP16 transactivation domain (aa 363-490). The resulting fused construct was inserted in a Sindbis vector. One day after the viral transfection, animals were monocularly deprived by eyelid suture for $4 \mathrm{~d}$. For the virus injection, a small hole was drilled in the skull and the tip of a 31 gauge Hamilton Syringe (Hamilton) containing the Sindbis virus (titer $=4.0 \times 10^{7}$ infectious units $/ \mathrm{ml}$ ) was stereotaxically positioned at an angle of $15-22^{\circ}$ from the midline and lowered $1 \mathrm{~mm}$ into the binocular region of the primary visual cortex. A volume of $2 \mu \mathrm{l}$ was injected at a rate of $0.1 \mu \mathrm{l}$ every $30 \mathrm{~s}$. Each animal received two injections $\sim 1 \mathrm{~mm}$ apart. After the period of monocular deprivation (MD), the animals were anesthetized, the deprived eye opened and either an optical imaging of intrinsic signals or a single-unit recording experiment was conducted. Please see supplemental methods (available at www.jneurosci.org as supplemental material) for surgical procedures. After the physiology experiments animals were perfused, the visual cortex collected and overexpression of the virus was assessed by immunohistochemistry.

Optical imaging of intrinsic signals. Optical imaging of intrinsic signals was performed with Imager $3001 \mathrm{VSD}+$ (Optical Imaging System) by using imaging methods slightly modified from those described previously (Medina et al., 2003, 2005, 2006; Krahe et al., 2005). An image of the vascular pattern was first obtained by illuminating the cortical surface with a green filter $(\sim 550 \mathrm{~nm})$ using a tungsten-halogen light source. Next, images of intrinsic signals were obtained using a red filter $(\sim 700$ $\mathrm{nm}$ ). Visual stimulation consisted of high-contrast square wave gratings $\left(8.75^{\circ}\right.$ dark phase $/ 1.25^{\circ}$ light phase $)$ generated by a 21 -inch monitor (Sony Trinitron) using SGT + graphics board and STIM software. Gratings were presented to each eye at an angle of $0^{\circ}, 45^{\circ}, 90^{\circ}$, or $135^{\circ}$ and drifted $\left(22.5^{\circ} / \mathrm{s}\right)$ in both directions along the axis orthogonal to the ori- entation of the grating. A single trial consisted of these four gratings and a blank screen presented to each eye for $9 \mathrm{~s}$ in a pseudorandom sequence, with data acquisition during the last $8 \mathrm{~s}$. A total of 20 trials were performed for each eye and the summed images were used to obtain singlecondition maps by subtracting responses to each eye from responses to a blank screen. In these images, dark areas correspond to regions that are visually responsive. In addition, differential maps were obtained by subtracting left eye from right eye single-condition maps. In these images, dark and light regions correspond to areas responsive to right and left eye stimulation, respectively. See supplemental methods (available at www. jneurosci.org as supplemental material) for additional information regarding imaging processing.

In vivo electrophysiology. Single-unit recordings were conducted using a glass-coated tungsten microelectrode with a $5 \mu \mathrm{m}$ exposed tip lowered into the primary visual cortex at $\sim 20^{\circ}$ to the vertical axis. To minimize sampling bias, single units used in this study were separated by at least $100 \mu \mathrm{m}$ along the electrode track. After the isolation of a single unit, the receptive field was mapped and the optimal stimulus orientation, direction, and velocity were determined qualitatively using a moving bar of light projected onto a tangent screen. OD, spontaneous activity, and number of spikes per stimulus were then quantitatively determined for each cell by presenting a computer-controlled bar of light to each eye. Each stimulus presentation consisted of the bar of light moving across the receptive field at the optimal orientation in one direction and back across in the opposite direction. To assess OD, the moving bar of light was presented to each eye separately at the optimal orientation. Spikes were collected during the 10 stimulus presentations by a computer using Spike 2 software (Cambridge Electronics Design) and peristimulus histograms were generated. Spontaneous activity was determined by recording activity in the absence of stimulation. At the conclusion of the experiment, ferrets were killed with Euthasol (0.6 ml $/ \mathrm{kg}$, i.p.; Delmarva).

Immunohistochemistry and confocal microscopy. Ferrets were perfused with cold saline followed by cold $4 \%$ paraformaldehyde solution. After 


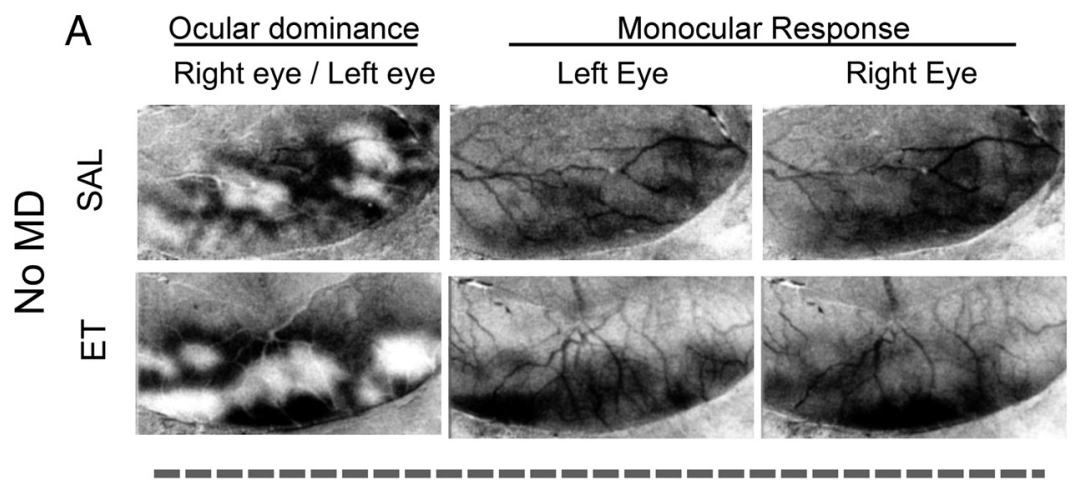

B
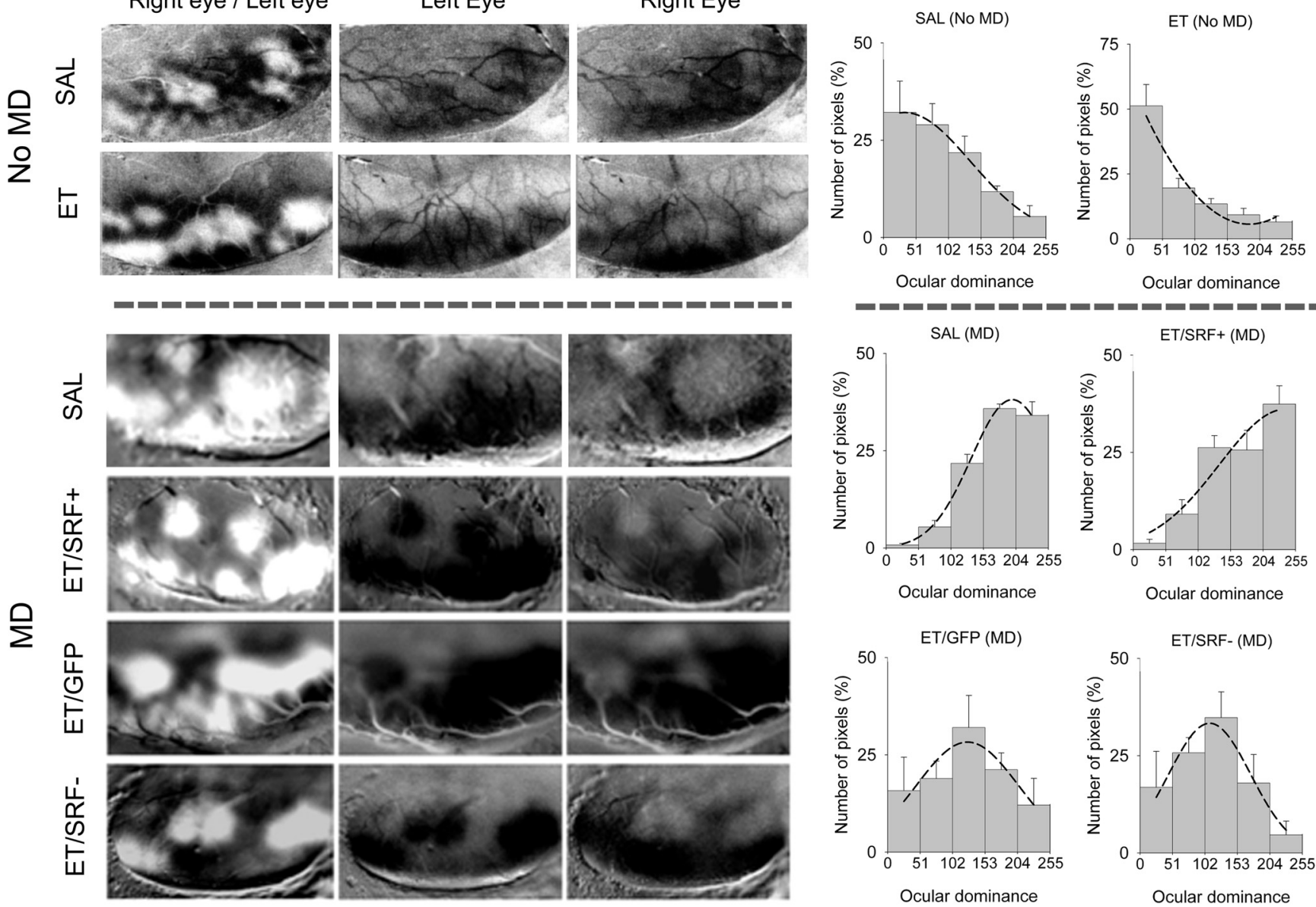

Ocular dominance
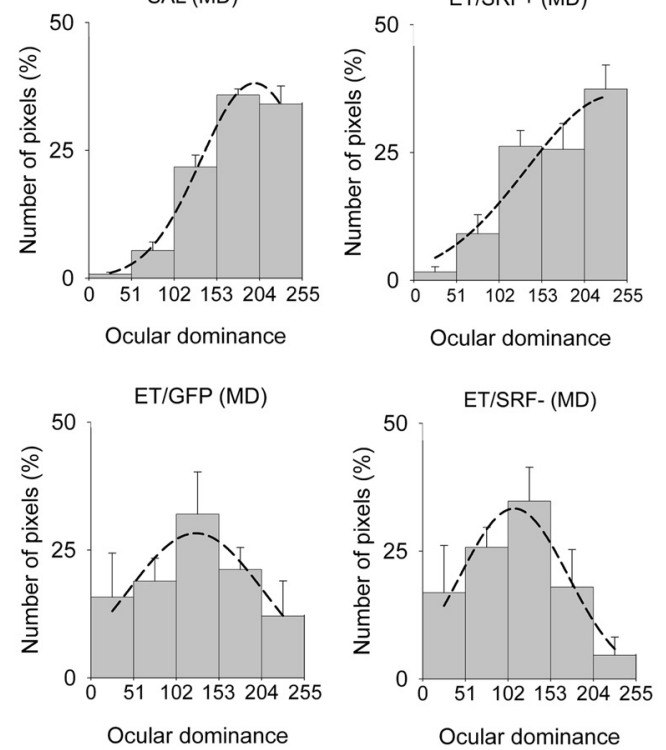

C
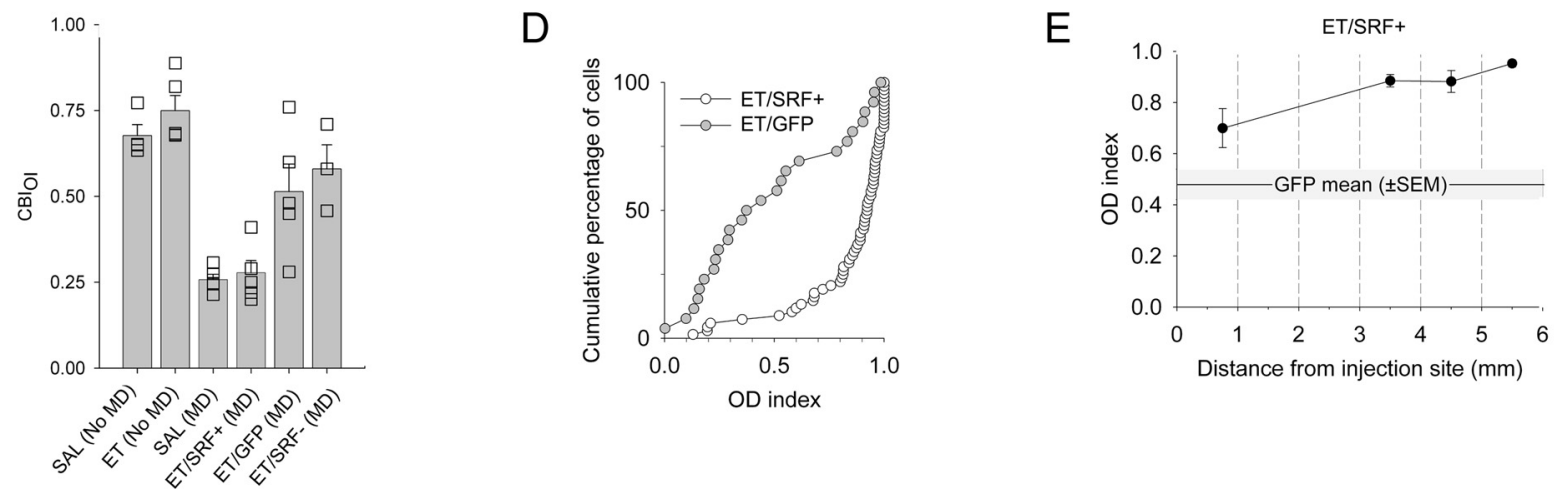

Figure 2. Optical imaging of intrinsic signals shows that SRF overexpression restores plasticity in alcohol-exposed animals. $\boldsymbol{A}$, First column shows ocular dominance maps of representative cases of each experimental group. Dark and light areas represent regions dominated by the right and left eye, respectively. In animals overexpressing SRF, monocular deprivation of the right eye resulted in a shiftin dominance toward the left eye. In contrast, in both animals, whether overexpressing GFP or a dominant-negative form of SRF, the deprived eye remained responsive. $\boldsymbol{B}$, Histograms display the percentage of pixels fitting in a grayscale (0, black; 255, white). Note the predominance of lighter pixels in animals infected with the virus carrying the constitutively active form of SRF (SRF + ), which indicates left (experienced) eye dominance. In contrast, note the predominance of black and gray pixels in animals infected with the virus carrying either GFP or a dominant-negativeform of SRF (SRF-), which indicates that the right (deprived) eye is still responsive. Saline (SAL) (no MD), $n=4$; ethanol (ET) (no MD), $n=5 ; \mathrm{SAL}$ (MD), $n=5 ; \mathrm{ET} / \mathrm{SRF}+(\mathrm{MD}), n=5 ; \mathrm{ET} / \mathrm{GFP}(\mathrm{MD}), n=5 ; \mathrm{ET} / \mathrm{SRF}-$ (MD), $n=3$. C, Mean contralateral bias indexes for all groups. Squares indicate individual animals. SRF + animals presented significantly lower $\mathrm{CBI}_{\mathrm{oi}} \mathrm{s}$ than GFP and SRF - (one-way ANOVA followed by Bonferroni, $p<0.05$ ). These findings indicate that SRF + rescues $\mathrm{OD}$ plasticity in alcohol-treated animals. D, Single-unit recordings show that SRF + overexpression restores plasticity in alcohol-exposed animals. Cumulative number of cells (as percentage) plotted as a function of the $0 D$ index for animals that received either SRF + or GFP. Note that in SRF + animals, the curve was skewed to the right, indicating an OD shift (most cells respond better to left eye stimulation). In contrast, in a GFP animal, many cells were still responsive to the right (deprived) eye. ET/SRF,$+ n=68$ neurons from three animals. ET/GFP, $n=26$ neurons from one animal. E, Single-unit recordings reveal that SRF+ expression rescued ocular dominance plasticity even far away from the injection site.

dissection of the occipital cortex, $50 \mu \mathrm{m}$ sections were obtained with a vibratome. For immunohistochemistry, the following primary antibodies were used at a concentration of 1:200: NeuN (Neuronal marker, mouse; Millipore Bioscience Research Reagents); GFAP (Astrocytic marker, rabbit; Dako); VP16 (Sindbis/SRF+ expression marker, mouse;
Santa Cruz Biotechnology), VP16 (Rabbit, Sigma-Aldrich); Flag (Sindbis/SRF - expression marker). The secondary antibodies were goat antirabbit (1:400, Alexa Fluor 594) and goat anti-mouse (1:200, Alexa Fluor 488). Tissue sections were alternately stained for VP16/GFAP and VP16/ NeuN. Sections were analyzed in a Leica TCS-SP2 AOBS confocal laser 
A

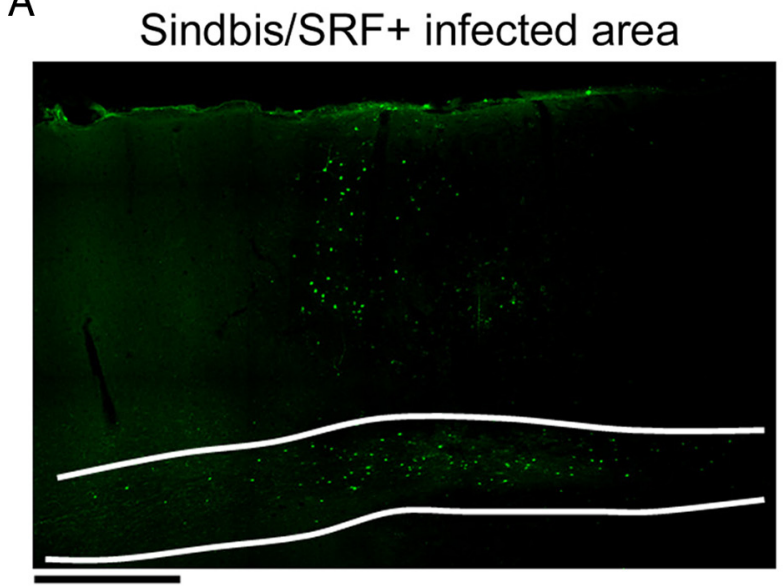

$500 \mu \mathrm{m}$
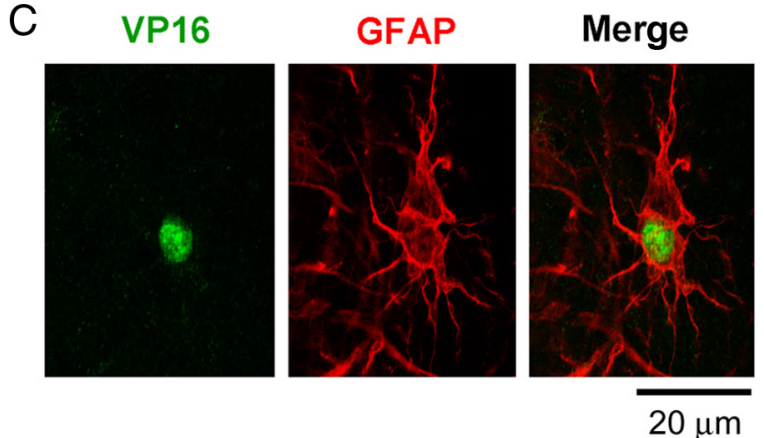

B
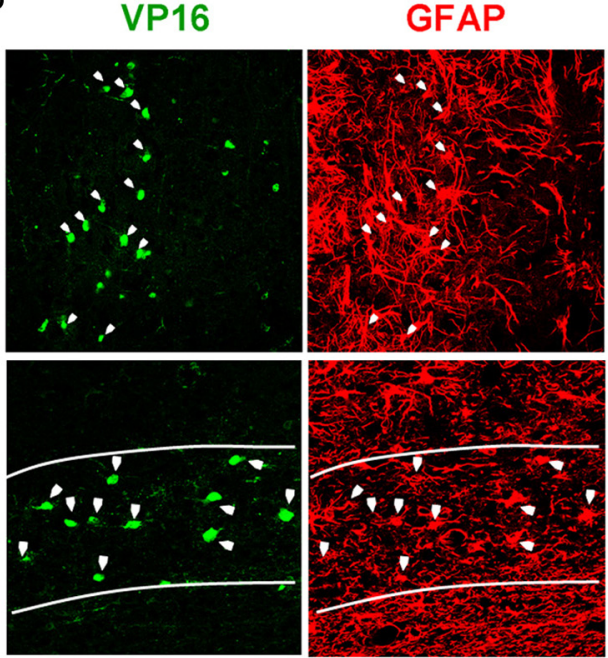

$50 \mu \mathrm{m}$

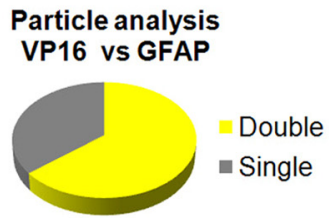

Z-Stack counting
VP16 vs GFAP

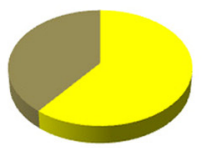

Double - Single
Particle analysis VP16 vs NeuN

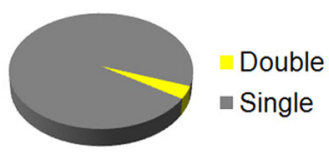

Z-Stack counting VP16 vs NeuN

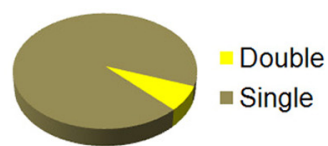

Figure 3. Laser confocal microscopy reveals that a cortical injection of Sindbis/SRF virus leads to successful expression of the transgenes. Most infected cells are astrocytes rather than neurons. $A$, Typical spread pattern of a Sindbis/SRF virus injection. Staining for the VP16 transactivation domain shows that the infection is present through all the columnar extent of the gray matter. Expression in the white matter (delimited by white lines) seems to be denser and spreads horizontally. B, Most cells positive for VP16 are also positive for the astrocyte marker GFAP. This was true for both gray and white matter (first and second rows, respectively). C, Image of an infected astrocyte. D, Quantification either by particle analysis (PA) or Z-stack double-labeling counting (ZS) (see supplemental methods, available at www.jneurosci.org as supplemental material) shows that most of the cells infected by Sindbis/SRF virus are astrocytes rather than neurons. VP16/GFAP colocalization: $\mathrm{PA}=64.4 \%, \mathrm{ZS}=60.8 \%$. VP16/NeuN colocalization: $\mathrm{PA}=3.6 \%, \mathrm{ZS}=7.1 \%$.

scanning microscope (inverted) with a spectrophotometer scan head, a high resolution Märzhäuser MCX-2 motorized XY stage and three confocal detectors. The system has five lasers: blue diode (405 nm), Argon $(458,476,488,514 \mathrm{~nm})$, green HeNe (543 nm), orange HeNe (594 nm), and red $\mathrm{HeNe}(633 \mathrm{~nm})$. Double staining (colocalization) was evaluated by two mutually reinforcing techniques: particle analysis and Z-stack counting. To perform particle analysis we first selected the two adjacent sections (VP16/GFAP, VP16/NeuN; one pair of sections for each animal; three animals used) that presented the greater number of infected cells. Confocal microscope tile scan images $(20 \times$ magnification $)$ were taken and analyzed using the IPLab software. To confirm the results obtained with the particle analysis, two independent observers evaluated 14 Z-stacks (seven VP16/GFAP; seven VP16/NeuN) from three animals. A typical Z-stack had the dimensions of $x=170 \mu \mathrm{m}, y=170 \mu \mathrm{m}, z=30$ $\mu \mathrm{m}$. The stack was covered by a $10 \times 7$ grid and each independent observer assessed whether a VP16-positive cell had double labeling (with GFAP or NeuN) or not. The total number of VP16-positive cells in VP16/GFAP and VP16/NeuN Z-stacks were 433 and 293, respectively.

\section{Results}

We investigated whether overexpression of SRF by Sindbis virus would improve OD plasticity in ferrets exposed to alcohol during the third trimester equivalent of human gestation, which is approximately P10-P30 in the ferret (Clancy et al., 2001; Medina et al., 2005). A summary of our experimental design can be seen in
Figure 1. After a prolonged alcohol-free period animals were injected with Sindbis/SRF+; Sindbis/GFP or Sindbis/SRF - in V1/V2 (Fig. $1 B, C$ ). We used optical imaging of intrinsic signals to create differential maps to assess changes in OD after monocular deprivation. Figure $2 \mathrm{~A}$ shows the left visual cortex of representative cases from each group analyzed. Dark and light areas in OD (differential) maps represent regions that respond preferentially to stimulation of the right and left eye respectively. In monocular response (single-condition) maps, dark regions represent areas that display strong responses to visual stimulation. Note that nondeprived animals (both saline and alcohol treated) (Fig. 2A) present the typical contralateral bias observed in ferrets (Issa et al., 1999; White et al., 1999; Medina et al., 2003). As expected, 4 d of MD in saline-treated animals lead to a striking shift in ocular dominance toward the experienced eye (Fig. 2A). Remarkably, after the same period of $\mathrm{MD}$, alcohol-treated animals that received the Sindbis/SRF + virus presented a similar shift (Fig. 2A), which indicates that OD plasticity was restored. Surprisingly, while the virus-infected area had a radius of $\sim 2 \mathrm{~mm}$, the shift in OD was observed along all the caudal extension of the visual cortex (V1, $\sim 6-10 \mathrm{~mm}$ medial to lateral) (Figs. $1 B, C, 2 A)$. In contrast, alcohol-treated animals that received either Sindbis/ GFP or Sindbis/SRF - presented only a very mild change in OD 
A

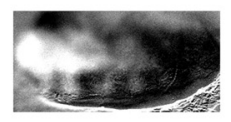

B

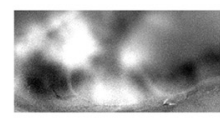

C

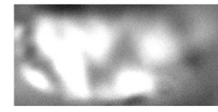

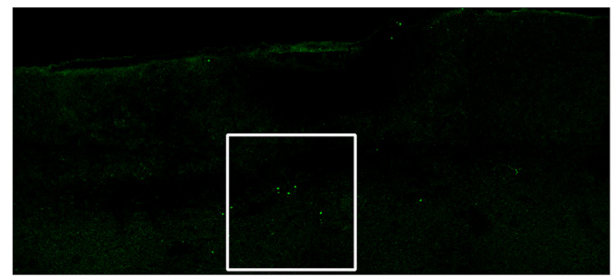
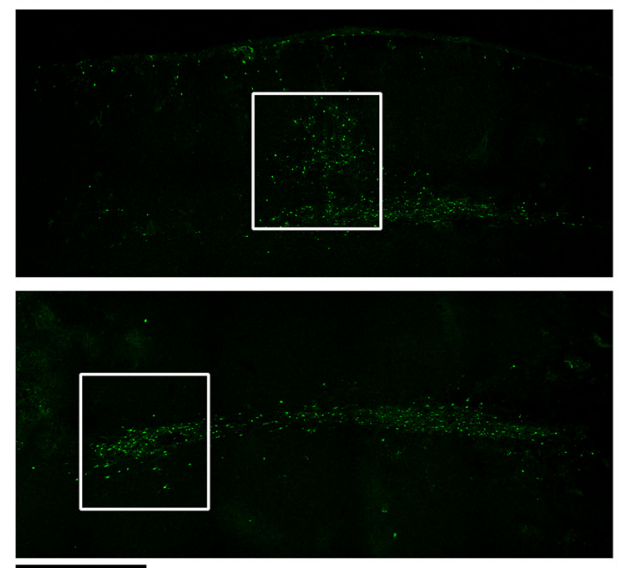

$800 \mu \mathrm{m}$

Figure 4. Effects of Sindbis/SRF injection on contralateral hemisphere in three alcohol-treated animals. $\boldsymbol{A}-\boldsymbol{C}$, First column shows differential maps obtained with optical imaging of intrinsic signals after $4 \mathrm{~d}$ of MD. Second column shows areas of highest virus infection revealed by immunohistochemistry for VP16. Third column shows magnifications of insert boxes. Note the high correlation between infection area and experienced eye dominance (white areas in differential maps).

(Fig. 2A), which confirm our previous findings that early alcohol exposure impairs OD plasticity (Medina et al., 2003; Medina and Ramoa, 2005). To quantify OD (differential) maps we calculated the pixel distribution along a 256 gray scale, divided in five class intervals, where $0-50$ and $204-255$ correspond to classes containing the darkest and lightest pixels, respectively. Accordingly, nondeprived animals (either saline or ethanol treated) presented histograms skewed to the left, which indicates contralateral eye dominance (Fig. $2 \mathrm{~B}$ ). In contrast, after $4 \mathrm{~d}$ of contralateral eyelid suture, saline-treated animals, as well as alcohol-treated animals that received Sindbis/SRF+, presented OD profiles skewed to the right, indicating the dominance of the ipsilateral eye (Fig. $2 B$ ). In contrast, alcohol-treated animals that received either Sindbis/ GFP or Sindbis/SRF - presented only modest changes in the OD profile. To further quantify these changes we created a contralateral bias index (CBI) (Fig. 1C). This index is defined as follows: $\left[\left(P_{0-50}-P_{204-255}\right)-\left(\left[P_{51-101}-P_{153-253}\right] / 2\right)+100\right] / 200$, where $P_{A-B}$ denotes the percentage of pixels with gray values between $A$ and $B$. A CBI close to 1.0 indicates a prevalence of darker pixels and right eye dominance. A CBI close to 0.0 indicates a prevalence of lighter pixels and left eye dominance. An ANOVA showed a significant $(F=10.09, \mathrm{df}=2, p=0.001)$ effect of treatment $(\mathrm{SRF}+, \mathrm{GFP}$, or SRF-). Post hoc analysis showed that alcohol-treated animals that received Sindbis/SRF+ had significantly smaller CBIs than animals that received GFP (Bonferroni, $p=0.01$ ) or SRF - (Bonferroni, $p=0.004$ ). To further assess the effects of SRF in improving OD plasticity we conducted singleunit recording experiments. The virus injection sites were easily identified in each animal and it was used as a landmark to place the electrode. Successful expression of the virus was confirmed by immunohistochemistry after the experiment. We created an OD index for each cell recorded using the following equation: LE/ ( $\mathrm{LE}+\mathrm{RE}$ ), where LE and RE stand for number of spikes elicited by stimulation of left and right eye, respectively. An OD index of 1.0
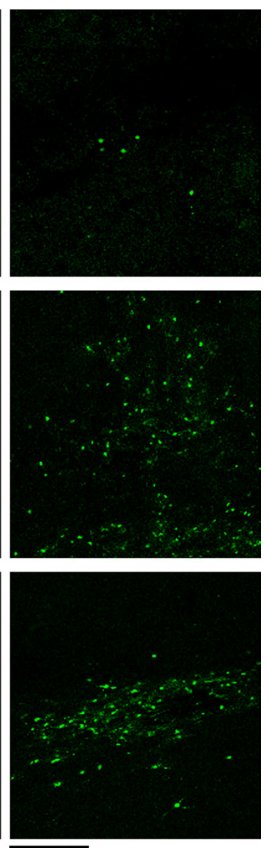

$200 \mu \mathrm{m}$ indicates a neuron that is responsive only to the left eye whereas an OD index of 0.0 indicates responses only to the right eye. Figure $1 D$ shows the cumulative distributions of neurons from alcohol-treated animals that were injected with Sindbis/ SRF+ or Sindbis/GFP. Note that the curve of SRF+ animals is completely skewed to the right when compared with GFP controls. This finding confirms our results with optical imaging showing that SRF restores OD plasticity in alcoholtreated animals. Interestingly, these results were observed even when recordings were made far from the injection site (Fig. $2 E$ ). A dominance of the experienced (ipsilateral) eye was present even when cells were recorded $3.5-5.5 \mathrm{~mm}$ from the injection site.

To confirm the expression of the virus we conducted immunohistochemistry in tandem with confocal laser microscopy. Figure $3 A$ shows the typical pattern of expression of the Sindbis/SRF+ virus. Note that cells positive for the VP16 transactivation domain can be seen in both gray and white matter (Fig. 3A). The presence of VP16-positive cells was observed in several sections and we calculated that the virus infection had an average diameter of $2300 \mu \mathrm{m}$ (SEM \pm 220 , $n=3$ animals). Interestingly, most VP16-positive cells could be identified as astrocytes due to double labeling with GFAP (Figs. $2 B, 3 B, 3 C)$. Further quantification using two different techniques showed that most infected cells could be identified as astrocytes (Fig. 3D). Surprisingly, only a small proportion of infected cells were positive for NeuN, a typical neuronal marker. One possible explanation for this difference is that the Sindbis virus could have infected and killed neurons during the first days of the infection. However, this possibility is unlikely since a similar pattern of infection (predominance of infected astrocytes rather than neurons) was observed after $24 \mathrm{~h}$ of the virus injection (supplemental Fig. S1, available at www.jneurosci.org as supplemental material). To evaluate the extension of the "plasticity enhancing" effect of SRF we made the virus injection on the contralateral (right) hemisphere of three alcohol-treated animals. After $4 \mathrm{~d}$ of $\mathrm{MD}$, optical imaging of intrinsic signals of the left hemisphere was performed to assess changes in OD. In the animal shown in Figure $4 A$, no change in the typical ferret OD profile was observed. However, the virus injection was not successful, as revealed by immunohistochemistry for VP16. In the second animal, a partial shift in OD and a moderate virus infection was observed (Fig. $4 B$ ). Finally, in the third animal, a strong shift in OD and a high degree of infection (in the white matter) was observed (Fig. 4C). These findings indicate a high correlation between Sindbis infection and OD shift, suggesting that overexpression of SRF might improve plasticity in contralateral hemisphere. The higher variability of the virus infection observed in this experiment might be due to the fact that all our equipment had to be adjusted to make the injections on the right hemisphere.

While it is known that SRF is normally expressed in the brain (Stringer et al., 2002; Knöll and Nordheim, 2009), we decided to assess whether endogenous levels of this transcription factor 
could be detected in visual cortex (Fig. $5 A-K)$. To accomplish that, we used a SRF antibody that tags to an amino acid sequence (aa 209-508, see Materials and Methods) that is not present in our SRF construct (Fig. 5G,H). Figure $5 A$ shows strong SRF expression in all cortical layers. While SRF expression was also observed in white matter, staining was drastically reduced. This antibody does not stain our SRF construct, and no colocalization between SRF and VP16 was observed. Endogenous SRF expression was also observed in animals that have not received Sindbis-SRF injection (data not shown). We also confirmed previous observations (Stringer et al., 2002; Knöll and Nordheim, 2009) showing the SRF has a high and low expression in neurons and astrocytes respectively (Fig. $5 D-F$ ). Next we wanted to confirm that our SindbisSRF virus lead to SRF expression. To accomplish that we used an antibody that tags the amino acids around the lysine 99 phosphorylation site (aa 97-101). This region is present in our SRF construct (Fig. $5 G, H)$. Figure $5 I-K$ shows a high SRF expression in VP16-positive cells. This finding confirms that our construct induces expression of SRF and supports the use of VP16 as a marker in our previous experiments. As Sindbis virus is well known to infect neurons in rodents (Ehrengruber, 2002), we sought to test whether this preference for astrocytes in ferrets is due to species differences. Confirming previous results in rodents, the typical preference of the Sindbis virus for neurons was observed in cortex and hippocampus (Fig. 6).

\section{Discussion}

Here we show that overexpression of SRF by Sindbis virus, long after the period of alcohol exposure, rescues OD plasticity in the ferret model of FASD. In addition to this exciting result, we obtained two intriguing findings: First, in ferrets we did not see the Sindbis preference for neurons that was described for rodents (Ehrengruber, 2002). In fact our results showed that most of the cells infected were astrocytes rather than neurons. The preference for astrocytes seen here is probably due to species differences, since in mice the virus infected mostly neurons (Fig. 6). Second, plasticity restoration was observed in almost all V1 rather than being restricted to the area within the infection site. A possible interpretation is that released SRF products may diffuse through the neuropil, or are transported by the blood or CSF. While surprising, the capacity of
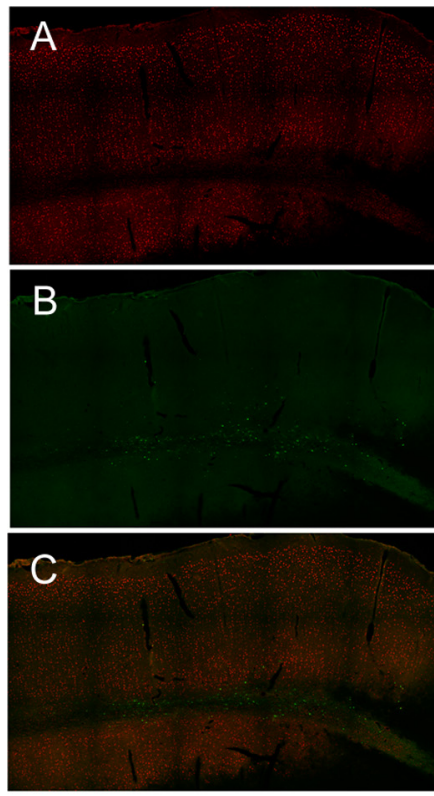

$400 \mu \mathrm{m}$
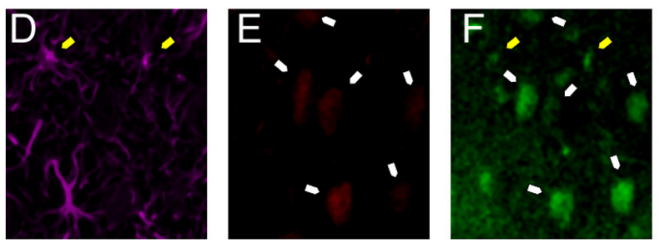

$30 \mu \mathrm{m}$

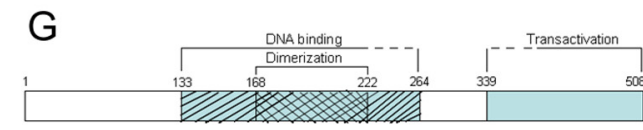

$\mathrm{H}$
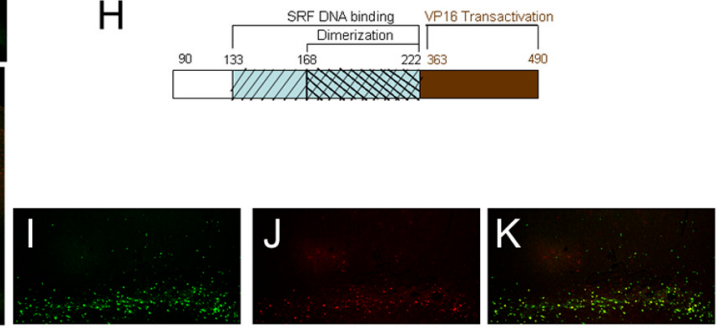

$200 \mu \mathrm{m}$
Figure 5. A, Tile scan of the visual cortex of the ferret using an anti-SRF antibody (Santa Cruz Biotechnology). This antibody attaches to the 209-508 amino acid sequence of the SRF transactivation domain. $\boldsymbol{B}$, Immunostaining for VP16 transactivation domain, which indicates cells infected by the virus. $\boldsymbol{C}$, Merge of the two pictures. Note that there is no colocalization of the endogenous SRF with the cells infected. Laser confocal microscopy reveals that SRF is abundant in neurons and is also present in some astrocytes. $\boldsymbol{D}-\boldsymbol{F}$, Note that NeuN-positive cells ( $\boldsymbol{E}$, red) are rich in $\operatorname{SRF}(\boldsymbol{F}$, green). White arrows in $\boldsymbol{E}$ and $\boldsymbol{F}$ indicate same cells. In GFAP-positive cells ( $\boldsymbol{D}$, magenta), SRF expression is either reduced or absent. Yellow arrows point to same cells. $\boldsymbol{G}, \boldsymbol{H}$, Schematic representation of the SRF molecule $(\boldsymbol{G})$ and our constitutively active SRF construct $(\boldsymbol{H})$. The construct was made by fusing the dimerization and DNA binding domains of SRF (aa 90-222) with the HSV VP16 transactivation domain (aa 363-490). The resulting fused construct was inserted into a Sindbis vector. Note that the construct lacks most of the sequence that is recognized by the SRF antibody used in $\boldsymbol{B}$ (aa 209-508). I-K, Using an SRF antibody that targets a sequence of amino acids that is present in our construct (aa 97-101; anti-SRF; ABCam), we were able to demonstrate that overexpression of our construct indeed increases SRF expression and that VP16 could be a good marker. I, VP16; J, SRF; $\boldsymbol{K}$, merge.
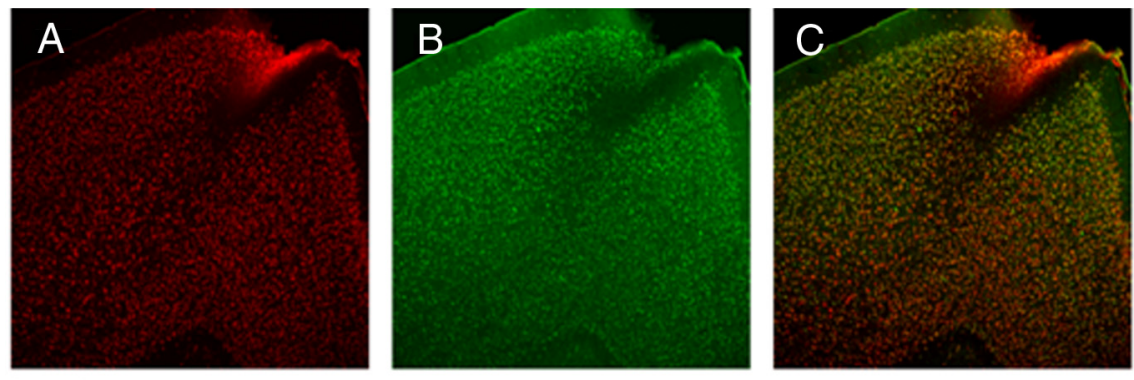

\section{$200 \mu \mathrm{m}$}
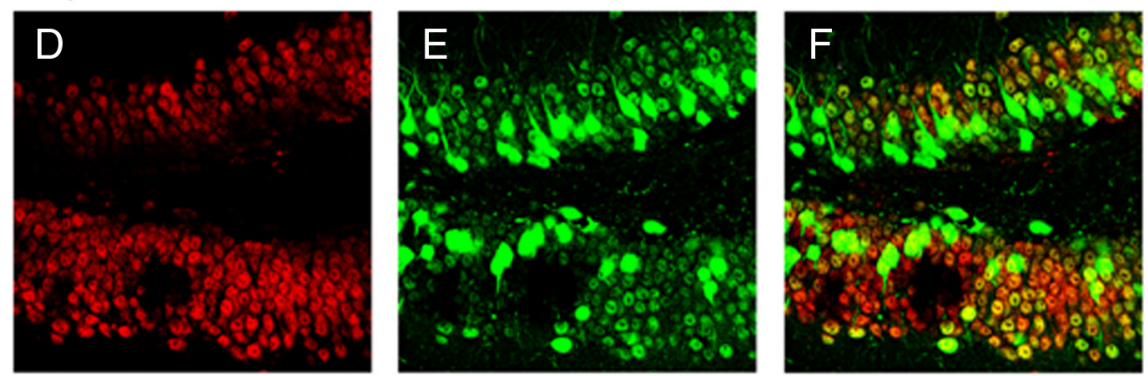

$\overline{40 \mu \mathrm{m}}$

Figure 6. Cell preference of the Sindbis virus is species dependent. $A-C$, Intraventricular injection of $3 \mu$ lof the Sindbis virus resulted in a massive infection of visual cortex neurons in the mouse. $\boldsymbol{A}$, NeuN; $\boldsymbol{B}$, SRF; $\boldsymbol{C}$, merge. $\boldsymbol{D}-\boldsymbol{F}$, Hippocampal injection of $1.5 \mu$ lof the Sindbis virus resulted in a massive infection of neurons in the mouse hippocampus. $\boldsymbol{D}$, NeuN; $\boldsymbol{E}$, SRF; $\boldsymbol{F}$, merge. 
brain cells to release signaling molecules and affect a large area had been demonstrated before. It was shown by independent groups that implantation of astrocytes overexpressing glial cell linederived neurotrophic factor (GDNF) provide extensive neuroprotection to dopaminergic neurons (Cunningham and $\mathrm{Su}$, 2002; Ericson et al., 2005). Moreover, the effects observed in these studies were not restricted to the injected site and increased levels of GDNF were observed even in the contralateral hemisphere (Cunningham and Su, 2002; Ericson et al., 2005). Recently, Stritt and colleagues provided evidence that activation of SRF can mediate the release of signaling molecules. They showed that lentiviral-mediated transfer of a constitutively active SRF construct in neurons dramatically affects maturation of oligodendrocytes (Stritt et al., 2009). In our present study, while most of the cells infected by the Sindbis-SRF construct were astrocytes, we observed an effect on neuronal plasticity. This finding suggests the intriguing possibility that activation of SRF in astrocytes may result in the production and release of plasticity-related factors, boosting neuronal plasticity in an extensive cortical area. However, we cannot discard the possibility that the few infected neurons are actually either the major players or significantly contribute to the SRF-mediated restoration of ocular dominance plasticity in alcohol-treated animals.

Our understanding of astrocyte function and its relation to neurons has dramatically changed in the last 20 years. Modern neuroscience considers astrocytes major players in brain development and plasticity rather than mere supportive cells, see for review (Stevens, 2008; Fellin, 2009). In addition to producing an intricate pattern of spontaneous and neuronal-evoked calcium oscillations, astrocytes can secrete glutamate (Parpura et al., 1994), D-serine (which potentiates the AMPA receptor) (Schell et al., 1995) and a constellation of plasticity related factors. Recently, studies from Ben Barres' lab provided convincing evidence that astrocytes can secrete molecules that can dramatically affect the establishment of synapses. For instance, this group showed that immature astrocytes can promote synaptogenesis through release of thrombospondins (Christopherson et al., 2005) and refinement of retinogeniculate synapses through secretion of C1q protein (Stevens et al., 2007). Astrocytes may also play an important role in synaptic plasticity. Recently, it was demonstrated that glial release of tumor necrosis factor $\alpha$ ( TNF $\alpha$ ) mediate the compensatory changes in synaptic strength that occur after an increase or decrease in global activity (homeostatic plasticity) (Beattie et al., 2002). In addition, TNF $\alpha$ KO mice have altered OD plasticity (Kaneko et al., 2008).

Astrocytes have also been linked to the establishment of the critical period of ocular dominance plasticity. Christian Müller described that the time of the maturation of astrocytes is coincident with the closure of the critical period. In addition, implantation of immature astrocytes in the primary visual cortex of adult cats reopens the critical period of ocular dominance plasticity (Müller and Best, 1989; Müller, 1992). While these findings strongly indicated a role for astrocytes in the regulation of critical period, the mechanisms that underlie this process were never elucidated. Our findings here suggest that astrocytes may also contribute to the process of ocular dominance plasticity, perhaps trough the release of plasticity-related factors, which could boost plasticity in neurons.

Since early alcohol exposure affects many cascades related to SRF activation (Davis et al., 1999; Luo and Miller, 1999; Kalluri and Ticku, 2003; Tsuji et al., 2003; Tang et al., 2006), as well as the secretory capacity of astrocytes (Tomás et al., 2005), it is plausible that a decrease of astrocytic-released molecules may contribute to the plasticity deficits seen in models of FASD. One possibility is that alcohol causes a reduction in the production and/or release of SRF-mediated molecules and the overexpression of this transcription factor bring these molecules to normal levels. This idea is supported by findings that show that early alcohol exposure can lead to an alteration in pathways that are known to activate SRF such as MAPK (Davis et al., 1999; Luo and Miller, 1999; Kalluri and Ticku, 2003; Tsuji et al., 2003; Tang et al., 2006) and RhoA (Joshi et al., 2006) as well as decrease the secretory capacity of astrocytes (Tomás et al., 2005). Alternatively, SRF function in astrocytes from alcohol-treated animals might be normal, and the beneficial effects of SRF overexpression may be a result of a compensatory boost of plasticity caused by the release of many plasticity-related molecules.

In conclusion, we show here that overexpression of SRF leads to a widespread plasticity enhancement in the visual cortex of ferrets early exposed to ethanol. Importantly, our results suggest the intriguing possibility that astrocytes are actually the major players in this restorative effect. Our findings contribute for our understanding of how early alcohol exposure affects astrocyte to neuron signaling and its effects on cortical plasticity. This information may be highly relevant to devise therapeutic interventions that will prevent or alleviate morbidity in FAS.

\section{References}

Alberti S, Krause SM, Kretz O, Philippar U, Lemberger T, Casanova E, Wiebel FF, Schwarz H, Frotscher M, Schütz G, Nordheim A (2005) Neuronal migration in the murine rostral migratory stream requires serum response factor. Proc Natl Acad Sci U S A 102:6148-6153.

Beattie EC, Stellwagen D, Morishita W, Bresnahan JC, Ha BK, Von Zastrow M, Beattie MS, Malenka RC (2002) Control of synaptic strength by glial TNFalpha. Science 295:2282-2285.

Chai J, Tarnawski AS (2002) Serum response factor: discovery, biochemistry, biological roles and implications for tissue injury healing. J Physiol Pharmacol 53:147-157.

Christopherson KS, Ullian EM, Stokes CC, Mullowney CE, Hell JW, Agah A, Lawler J, Mosher DF, Bornstein P, Barres BA (2005) Thrombospondins are astrocyte-secreted proteins that promote CNS synaptogenesis. Cell 120:421-433

Clancy B, Darlington RB, Finlay BL (2001) Translating developmental time across mammalian species. Neuroscience 105:7-17.

Coles CD, Platzman KA, Lynch ME, Freides D (2002) Auditory and visual sustained attention in adolescents prenatally exposed to alcohol. Alcohol Clin Exp Res 26:263-271.

Cunningham LA, Su C (2002) Astrocyte delivery of glial cell line-derived neurotrophic factor in a mouse model of Parkinson's disease. Exp Neurol 174:230-242.

Davis MI, Szarowski D, Turner JN, Morrisett RA, Shain W (1999) In vivo activation and in situ BDNF-stimulated nuclear translocation of mitogen-activated/extracellular signal-regulated protein kinase is inhibited by ethanol in the developing rat hippocampus. Neurosci Lett 272:95-98.

Ehrengruber MU (2002) Alphaviral vectors for gene transfer into neurons. Mol Neurobiol 26:183-201.

Ericson C, Georgievska B, Lundberg C (2005) Ex vivo gene delivery of GDNF using primary astrocytes transduced with a lentiviral vector provides neuroprotection in a rat model of Parkinson's disease. Eur J Neurosci 22:2755-2764.

Etkin A, Alarcón JM, Weisberg SP, Touzani K, Huang YY, Nordheim A, Kandel ER (2006) A role in learning for SRF: deletion in the adult forebrain disrupts LTD and the formation of an immediate memory of a novel context. Neuron 50:127-143.

Fellin T (2009) Communication between neurons and astrocytes: relevance to the modulation of synaptic and network activity. J Neurochem 108:533-544.

Frank DA, Greenberg ME (1994) CREB: a mediator of long-term memory from mollusks to mammals. Cell 79:5-8.

Issa NP, Trachtenberg JT, Chapman B, Zahs KR, Stryker MP (1999) The critical period for ocular dominance plasticity in the ferret's visual cortex. J Neurosci 19:6965-6978. 
Joshi S, Guleria RS, Pan J, Bayless KJ, Davis GE, Dipette D, Singh US (2006) Ethanol impairs Rho GTPase signaling and differentiation of cerebellar granule neurons in a rodent model of fetal alcohol syndrome. Cell Mol Life Sci 63:2859-2870.

Kalluri HS, Ticku MK (2003) Regulation of ERK phosphorylation by ethanol in fetal cortical neurons. Neurochem Res 28:765-769.

Kaneko M, Stellwagen D, Malenka RC, Stryker MP (2008) Tumor necrosis factor-alpha mediates one component of competitive, experiencedependent plasticity in developing visual cortex. Neuron 58:673-680.

Klug MG, Burd L (2003) Fetal alcohol syndrome prevention: annual and cumulative cost savings. Neurotoxicol Teratol 25:763-765.

Knöll B, Nordheim A (2009) Functional versatility of transcription factors in the nervous system: the SRF paradigm. Trends Neurosci 32:432-442.

Knöll B, Kretz O, Fiedler C, Alberti S, Schütz G, Frotscher M, Nordheim A (2006) Serum response factor controls neuronal circuit assembly in the hippocampus. Nat Neurosci 9:195-204.

Kornhauser JM, Cowan CW, Shaywitz AJ, Dolmetsch RE, Griffith EC, Hu LS, Haddad C, Xia Z, Greenberg ME (2002) CREB transcriptional activity in neurons is regulated by multiple, calcium-specific phosphorylation events. Neuron 34:221-233.

Krahe TE, Medina AE, de Bittencourt-Navarrete RE, Colello RJ, Ramoa AS (2005) Protein synthesis independent plasticity mediates rapid and precise recovery of deprived eye responses. Neuron 48:329-343.

Krahe TE, Wang W, Medina AE (2009) Phosphodiesterase inhibition increases CREB phosphorylation and restores orientation selectivity in a model of fetal alcohol spectrum disorders. PLos ONE 4:e6643.

Krahe TE, Paul AP, Medina AE (2010) Phosphodiesterase type 4 inhibition does not restore ocular dominance plasticity in a ferret model of fetal alcohol spectrum disorders. Alcohol Clin Exp Res 34:1-6.

Lamprecht R (1999) CREB: a message to remember. Cell Mol Life Sci 55: $554-563$.

Luo J, Miller MW (1999) Transforming growth factor beta1-regulated cell proliferation and expression of neural cell adhesion molecule in B104 neuroblastoma cells: differential effects of ethanol. J Neurochem 72:2286-2293.

Margret CP, Chappell TD, Li CX, Jan TA, Matta SG, Elberger AJ, Waters RS (2006) Prenatal alcohol exposure (PAE) reduces the size of the forepaw representation in forepaw barrel subfield (FBS) cortex in neonatal rats: relationship between periphery and central representation. Exp Brain Res 172:387-396

Mattson SN, Gramling L, Riley EP, Delis DC, Jones KL (1996) Global-local processing in children prenatally exposed to alcohol. Child Neuropsychol 2:165-175.

Medina AE, Ramoa AS (2005) Early alcohol exposure impairs ocular dominance plasticity throughout the critical period. Brain Res Dev Brain Res 157:107-111.

Medina AE, Krahe TE (2008) Neocortical plasticity deficits in fetal alcohol spectrum disorders: lessons from barrel and visual cortex. J Neurosci Res 86:256-263.

Medina AE, Krahe TE, Coppola DM, Ramoa AS (2003) Neonatal alcohol exposure induces long-lasting impairment of visual cortical plasticity in ferrets. J Neurosci 23:10002-10012.

Medina AE, Krahe TE, Ramoa AS (2005) Early alcohol exposure induces persistent alteration of cortical columnar organization and reduced orientation selectivity in the visual cortex. J Neurophysiol 93:1317-1325.

Medina AE, Krahe TE, Ramoa AS (2006) Restoration of neuronal plasticity by a phosphodiesterase type 1 inhibitor in a model of fetal alcohol exposure. J Neurosci 26:1057-1060.

Montminy MR, Gonzalez GA, Yamamoto KK (1990) Regulation of cAMPinducible genes by CREB. Trends Neurosci 13:184-188.

Morris TA, Jafari N, Rice AC, Vasconcelos O, DeLorenzo RJ (1999) Persistent increased DNA-binding and expression of serum response factor occur with epilepsy-associated long-term plasticity changes. J Neurosci 19:8234-8243.

Müller CM (1992) Astrocytes in cat visual cortex studied by GFAP and S-100 immunocytochemistry during postnatal development. J Comp Neurol 317:309-323

Müller CM, Best J (1989) Ocular dominance plasticity in adult cat visual cortex after transplantation of cultured astrocytes. Nature 342:427-430.

Parpura V, Basarsky TA, Liu F, Jeftinija K, Jeftinija S, Haydon PG (1994) Glutamate-mediated astrocyte-neuron signaling. Nature 369:744-747.

Pláteník J, Kuramoto N, Yoneda Y (2000) Molecular mechanisms associated with long-term consolidation of the NMDA signals. Life Sci 67:335-364.

Powrozek TA, Zhou FC (2005) Effects of prenatal alcohol exposure on the development of the vibrissal somatosensory cortical barrel network. Brain Res Dev Brain Res 155:135-146.

Ramanan N, Shen Y, Sarsfield S, Lemberger T, Schütz G, Linden DJ, Ginty DD (2005) SRF mediates activity-induced gene expression and synaptic plasticity but not neuronal viability. Nat Neurosci 8:759-767.

Rasmussen C, Horne K, Witol A (2006) Neurobehavioral functioning in children with fetal alcohol spectrum disorder. Child Neuropsychol 12:453-468.

Rema V, Ebner FF (1999) Effect of enriched environment rearing on impairments in cortical excitability and plasticity after prenatal alcohol exposure. J Neurosci 19:10993-11006.

Schell MJ, Molliver ME, Snyder SH (1995) D-Serine, an endogenous synaptic modulator: localization to astrocytes and glutamate-stimulated release. Proc Natl Acad Sci U S A 92:3948-3952.

Schratt G, Philippar U, Berger J, Schwarz H, Heidenreich O, Nordheim A (2002) Serum response factor is crucial for actin cytoskeletal organization and focal adhesion assembly in embryonic stem cells. J Cell Biol 156:737-750

Shaywitz AJ, Greenberg ME (1999) CREB: a stimulus-induced transcription factor activated by a diverse array of extracellular signals. Annu Rev Neurosci 68:821-861.

Silva AJ, Kogan JH, Frankland PW, Kida S (1998) CREB and memory. Annu Rev Neurosci 21:127-148.

Stevens B (2008) Neuron-astrocyte signaling in the development and plasticity of neural circuits. Neurosignals 16:278-288.

Stevens B, Allen NJ, Vazquez LE, Howell GR, Christopherson KS, Nouri N, Micheva KD, Mehalow AK, Huberman AD, Stafford B, Sher A, Litke AM, Lambris JD, Smith SJ, John SW, Barres BA (2007) The classical complement cascade mediates CNS synapse elimination. Cell 131:1164-1178.

Stringer JL, Belaguli NS, Iyer D, Schwartz RJ, Balasubramanyam A (2002) Developmental expression of serum response factor in the rat central nervous system. Brain Res Dev Brain Res 138:81-86.

Stritt C, Stern S, Harting K, Manke T, Sinske D, Schwarz H, Vingron M, Nordheim A, Knöll B (2009) Paracrine control of oligodendrocyte differentiation by SRF-directed neuronal gene expression. Nat Neurosci 12:418-427.

Tang N, He M, O'Riordan MA, Farkas C, Buck K, Lemmon V, Bearer CF (2006) Ethanol inhibits L1 cell adhesion molecule activation of mitogenactivation protein kinases. J Neurochem 96:1480-1490.

Tomás M, Marín P, Megías L, Egea G, Renau-Piqueras J (2005) Ethanol perturbs the secretory pathway in astrocytes. Neurobiol Dis 20:773-784.

Tsuji R, Guizzetti M, Costa LG (2003) In vivo ethanol decreases phosphorylated MAPK and p70s6 in the developing rat brain. Neuroreport 14:1395-1399.

Uecker A, Nadel L (1996) Spatial locations gone awry: object and spatial memory deficits in children with fetal alcohol syndrome. Neuropsychologia 34:209-223.

White LE, Bosking WH, Williams SM, Fitzpatrick D (1999) Maps of central visual space in ferret V1 and V2 lack matching inputs from the two eyes. J Neurosci 19:7089-7099. 